\title{
0 processo de empoderamento de idosas integrantes do núcleo de estudos da terceira idade da UFSC
}

\author{
Teresa Kleba Lisboa \\ tkleba@gmail.com \\ Cristiane Vieira \\ ufsc-cristiane@gmail.com
}

\section{Resumo}

O presente artigo foi elaborado a partir de uma experiência de estágio no Projeto Intercâmbio Comunitário em Gerontologia do Núcleo de Estudos da Terceira Idade da Universidade Federal de Santa Catarina, entre o período de março de 2009 a julho de 2012, que resultou no Trabalho de Conclusão de Curso de Graduação em Serviço Social da UFSC. A temática do estudo é centrada no processo de empoderamento das idosas integrantes do projeto, o qual foi compreendido a partir dos conceitos de autonomia e protagonismo. O método utilizado seguiu as premissas dos relatos orais, na modalidade trajetórias de vida de cinco mulheres idosas voluntárias e inseridas no NETI. As entrevistas foram realizadas no período de 23 de abril a 28 de junho de 2012. Os relatos mostram que as idosas se apropriaram de conhecimentos para a ação multiplicadora, atuando em diferentes etapas do projeto, conciliando a vida em família e demais afazeres para levarem informações para grupos de idosos, nos diversos municípios de Santa Catarina, compartilhando conhecimentos e experiências sobre higiene, promoção da saúde, prevenção de doenças sexualmente transmissíveis, direitos e exercício da cidadania, enfim, o bom envelhecer entre os seus pares. A análise dos relatos torna perceptível a construção do ser empoderada, confirmando a hipótese de que essas mulheres, a partir de sua inserção no NETI, em especial no Intercâmbio Comunitário em Gerontologia, desenvolveram autoestima e autoconfiança, ampliaram a capacidade de ação e a vontade de viver, através do convívio entre seus pares geracionais e intergeracionais.

Palavras-chave: Mulher idosa. Autonomia. Protagonismo. Empoderamento.

\section{The process of empowerment of elderly members in the center for studies of the third age at UFSC}

\section{Abstract}

The present study was carried out from the experience of an intern in the Community Exchange Project in Gerontology at the Center of Studies to the Elderly in the Federal University of Santa Catarina, in the period between March 2009 and July 2012. It resulted in the conclusion work to the Under Graduation Course on Social Service, at UFSC. The theme of the research is focused on the process of elderly women's empowerment that were members of the Project, which was understood from the concepts of autonomy and leadership. The used method followed the assumptions of the oral stories, in the modality of life histories of five elderly women that volunteered at NETI. The interviews were conducted from April 23 to June 28, 2012. The reports show that the elderly women got knowledge for a multiplier action, acting in different stages of 
the Project, reconciling family life and other chores to bring information to the elderly groups, in several municipalities of Santa Catarina. They shared knowledge and experiences on hygiene, health promotion, prevention of sexually transmitted diseases, rights and citizenship; in short, the good aging among their peers. The reports' analysis shows the construction of the empowered person, confirming the hypothesis that these women, from their insertion in NETI and particularly in the Exchange Community on Gerontology, developed their self-esteem and self-confidence. They also expanded the capacity of action and the will to live through the interaction among their generational and intergenerational peers.

Key words: Elderly woman. Autonomy. Leadership. Empowerment.

\section{INTRODUÇÃO}

As primeiras ideias sobre a introdução de um trabalho prático na área gerontológica na Universidade Federal de Santa Catarina foram apresentadas à Pró-Reitoria de Assuntos Estudantis e de Extensão em março de 1982, pelas professoras Neusa Mendes Guedes e Lucia Hisako Takase Gonçalves ${ }^{1}$. Relembrando essa importante data na história, o ano de 2012 foi pleno de comemorações para festejar os trinta anos de criação do Núcleo de Estudos da Terceira Idade (NETI) na UFSC.

A criação do NETI, na época, contou com o apoio do então Pró-Reitor de Assuntos Estudantis e de Extensão, Professor Hamilton Savi, bem como da então Diretora do Departamento de Assuntos Culturais (DAC), Professora Zuleica Lenzi. As atividades do núcleo foram sendo introduzidas no âmbito universitário de forma gradativa, através de palestras e discussões sobre o envelhecimento enquanto uma ação socioeducativa (GUEDES, 1997), e, no mês de agosto de 1983, o Núcleo de Estudos da Terceira Idade (NETI) foi oficialmente criado, vinculado à Pró-Reitoria de Assuntos Estudantis e de Extensão, através da Portaria 0484/GR/83.

Em entrevista concedida a "Serviço Social em Revista"2 em novembro de 2008, a Professora Neusa Mendes Guedes afirma a importância do NETI como um campo de Extensão:

'[...] o que a gente pode perceber, com a Extensão do NETI, foi o envolvimento de todas as áreas (uma interdisciplinaridade), esse era o nosso objetivo. A Universidade é a casa do saber; é na universidade que se discute e se realiza as pesquisas sobre diversos assuntos; se a universidade não fizer isso, quem é que vai fazer? O campo da Extensão na universidade é um excelente campo de estágio e de pesquisa' (SERVIÇO SOCIAL EM REVISTA, 2009, p. 45).

Uma das propostas do NETI é capacitar a pessoa idosa para atuar como agente multiplicadora ${ }^{3}$. Nessa perspectiva, o núcleo expandiu a atuação dos (as) idosos (as) para a região da Grande Florianópolis e até mesmo para as cidades do interior do Estado de Santa Catarina. Essa ação foi fundamental para a discussão e criação de políticas de proteção da pessoa idosa, como o Estatuto do Idoso, criado em 2003, o Conselho Estadual do Idoso, que surgiu em 1990, e o Conselho Municipal do Idoso, criado em 1998.

Os objetivos do NETI permanecem os mesmos desde a sua criação: a) ampliar e sistematizar o conhecimento da Gerontologia; b) formar recursos humanos nos diversos níveis; c) manter atividades

1 Fundadoras do Núcleo de Estudos da Terceira Idade: Profa. e Assistente Social Neusa Mendes Guedes (in memoriam) e Profa. Dra. em Enfermagem Lúcia HisakoTakase Gonçalves.

2 Revista comemorativa aos 50 anos do Curso de Serviço Social na UFSC, organizada pelas Profas. Rosana Martinelli e Teresa Kleba Lisboa, UFSC, 2009.

3 Alunos que, após um período de três anos de formação, no Curso de Monitores da Ação Gerontológica, passam a atuar como multiplicadores, ou seja, passam seus conhecimentos para seus pares na condição de voluntários. 
interdisciplinares e interinstitucionais; d) assessorar entidades na organização de programas de valorização da pessoa idosa; e) oferecer subsídios para uma política de resgate da pessoa idosa na sociedade brasileira. (NETI)

Vale ressaltar que a maioria das pessoas que se inscrevem nas atividades do NETI são mulheres. Segundo registros institucionais, no ano de 2008, o núcleo contava com uma participação de 12\% de homens para $88 \%$ de mulheres matriculadas nos diversos cursos. Em 2012, o percentual de homens diminuiu para $11 \%$ (77 homens), enquanto que o de mulheres aumentou para $89 \%$, ou seja, 603 mulheres inscritas. Conforme Paschoal, os homens idosos apresentam mais resistência em participar de grupos, porque:

[...] se fragilizam mais que as mulheres no envelhecimento. Talvez a função social de provedor, de ser obrigado a demonstrar força, no trabalho, na família, nas relações amorosas, durante todo o tempo, deixe a ele poucas possibilidades de se adequar num momento declínio de força e poder (PASCHOAL, 2006, p. 89).

Em relação ao processo de empoderamento de pessoas idosas, Lisboa (2012) destaca que é importante levar em conta a realidade social na qual os idosos estão inseridos, relacionando esta com os vários desdobramentos que repercutem nas questões de acolhimento pela família, autonomia, liberdade de escolha, acesso a moradia, atendimento à saúde, discriminação de raça/etnia, entre outros fatores que possam ser motivo de exclusão social.

O empoderamento na fase do envelhecimento, para Lisboa (2012), é definido como um processo que ajuda as pessoas a firmarem seu controle sobre os fatores que afetam seu envelhecimento, quer seja na área da saúde, quer seja na área de uma remuneração que garanta a sua sobrevivência ou de uma ocupação remunerada. A categoria empoderamento também é utilizada como sinônimo de: habilidades de enfrentamento, suporte mútuo, organização comunitária, sistema de suporte, participação da vizinhança, eficiência pessoal, competência, autoestima e autossuficiência.

Nesse sentido, espaços como Centros de Convivência e Universidades Abertas para a Terceira Idade são procurados pelos idosos, uma vez que proporcionam a inclusão dos mesmos em projetos, como o Projeto Intercâmbio Comunitário em Gerontologia (PICG), que foi campo estágio e que será abordado a seguir.

Material e Métodos

O Projeto Intercâmbio Comunitário em Gerontologia (PICG) figura como um dos Projetos de Extensão oferecidos pela UFSC através do NETI e foi criado, no ano de 1993, pela Assistente Social Matilde Vieira. $\mathrm{Na}$ época, o projeto tinha como objetivo contribuir com a mobilização e implementação de programas gerontológicos junto às prefeituras municipais catarinenses quando ainda não existiam políticas de atenção à pessoa idosa no Brasil ${ }^{4}$. A dinâmica no estabelecimento de parcerias foi coordenada pelo NETI, com o apoio do gabinete da Reitoria (UFSC) e dos prefeitos de alguns municípios. Como pré-requisito para participar do projeto (representando o NETI), era necessário ser egresso do Curso de Formação de Monitores da Ação Gerontológica (CFMAG/NETI) ${ }^{5}$. Após participarem do Curso de Formação de Monitores, as idosas representando o NETI levavam aos grupos visitados informações sobre seus direitos, o que é cidadania, como viver em comunidade, prevenção de doenças e orientações a respeito da alimentação. Até novembro de 2007, foram visitados 54 municípios do Estado de Santa Catarina, totalizando 152.331 pessoas atingidas pelo projeto. Após uma década e meia de funcionamento e com o falecimento da coordenadora, a assistente social Matilde Vieira, o PICG passou por reformulações.

De 2005 a 2011, o PICG passou a ser coordenado pela Professora Ângela Maria Alvarez, oriunda do Departamento de Enfermagem da UFSC, a qual na época também respondia pela coordenação do NETI.

4 As legislações e políticas dirigidas à pessoa idosa criaram um mecanismo de proteção reforçando os direitos à pessoa idosa. Entre elas, pode-se citar: Lei Orgânica da Assistência Social - Lei n. 87420/43; A Política Nacional do Idoso - Lei n. 8742/94, que regulamenta a Política Nacional do Idoso; Estatuto do Idoso - Lei n. 10.74/ 93; Política Nacional de Assistência Social I (PNAS) - Resolução CNAS n. 145/2004; Decreto n. 5296/20004, que regulamenta a Lei de Acessibilidade; Portaria n. 2528/2006, que aprova a Política de Saúde para a Pessoa Idosa.

5 


\section{\begin{tabular}{l|l} 
Extensio & Relato de Experiência
\end{tabular}}

Nesse período, o PICG passou a atuar na área de abrangência da Grande Florianópolis, com os seguintes objetivos: a) capacitar idosos egressos no Curso de Formação de Monitores da Ação Gerontologia para atuarem junto aos grupos de convivência de idosos do município de Florianópolis; b) estimular a formação de lideranças de pessoas idosas capazes de mobilizar e transformar a realidade político-social das comunidades em que estão inseridas; c) difundir uma nova mentalidade ante o processo de envelhecimento junto aos grupos de convivência do município, que possam traduzir-se em comportamentos participativos para o conjunto da população idosa; d) avaliar as atividades desenvolvidas com vistas à produção de conteúdos acadêmicos (artigos, relatórios e comunicação em eventos científicos).

Uma demanda apresentada em 2007 pela Secretaria Municipal da Saúde de Florianópolis foi a de realizar atividades de educação e prevenção de doenças sexualmente transmissíveis, em razão de um crescimento acentuado de portadores de DST/AIDS na faixa etária de 60 anos ou mais ${ }^{6}$. Assim, o projeto passou a atuar na sensibilização e conscientização da mencionada doença junto às comunidades com grande repercussão no sentido de contribuir com a redução da incidência dos casos de HIV/AIDS nas pessoas com idade igual ou acima de 60 anos $^{7}$; sensibilizá-las sobre o HIV/AIDS; criar espaços de discussão permanente nos grupos de terceira idade sobre DSTs. O projeto contou com a parceria e participação das Secretarias Municipais de Florianópolis, na área da Saúde através da Vigilância Epidemiológica, e na área de Desenvolvimento Social através da Gerência do Idoso e Conselho Municipal do Idoso. Na ocasião, o projeto conseguiu envolver pessoas idosas participantes dos cursos do Núcleo de Estudos da Terceira Idade, para atuarem como facilitadoras no processo de educação para a prevenção de DST/AIDS com idosos dos 107 grupos de convivência existentes no município de Florianópolis.

Concorda-se com Madureira et al. (2005), que o PICG veio difundir uma nova mentalidade sobre o processo de envelhecimento, criando uma nova perspectiva de vida, uma consciência crítica e reflexiva na sociedade catarinense.

Em 2012, o projeto passou a ser coordenado pela professora Jordelina Schier, integrante do Departamento de Enfermagem, que também responde pela coordenação do NETI. Os objetivos do projeto mantiveram-se, e atualmente (2012) suas ações com relação à capacitação de idosos estão sendo oferecidas através das temáticas que abrangem o tema da Previdência Social e Cidadania, bem como na formação do Grupo de Estudos sobre Política e Envelhecimento. Ao ganhar visibilidade, o protagonismo da população idosa desponta como um novo fenômeno social, contribuindo para ressignificar o olhar sobre a questão do envelhecimento por parte de diversos profissionais que atuam na área, bem como pelos diversos segmentos da sociedade.

Nesse sentido, esse novo fenômeno refletiu também na atuação dos profissionais de Serviço Social, que passaram a vivenciar uma nova expressão da questão social, que não era valorizada até então. O Serviço Social se faz presente junto ao NETI, efetivando a mediação entre o compromisso com os desdobramentos da questão social no processo de envelhecimento, e o propósito de viabilizar e garantir os direitos sociais dos idosos, acompanhando as disposições dos instrumentos legais (Código de Ética e Lei da Regulamentação da Profissão), que preveem a inclusão social das pessoas idosas em projetos que contribuem para o seu bem-estar. Visando garantir esse espaço de direitos, o Serviço Social também presta assessoria técnica a

6 Dados do Ambulatório de Aids, do Idoso do Hospital Emílio Ribas, em São Paulo - um dos principais centros de referência no tratamento da doença no país - mostram que, nos últimos três ano, o total de pessoas com mais de 60 anos atendidas mensalmente no serviço aumentou 400\%. Saltou de 20, em 2005, para 100, em 2007. Os casos de AIDS na população idosa alcançaram índices alarmantes em 5 de junho de 2012. De acordo com o jornal local Vida e Cidadania, de 2009, em Santa Catarina, foram notificados 21.127casos de AIDS no período de 1984 a 2009. Disponível em: \ornalvidaecidadania@ hotmail.com. Abril de 2009. 
dois projetos do NETI, que são: o Curso de Formação de Monitores da Ação Gerontológica (CFMAG), e o PICG, que é objeto desse artigo. Junto ao Projeto Intercâmbio Comunitário em Gerontologia (PICG), o Serviço Social tem atuado nas áreas de pesquisas, planejamento, execução e avaliação em consonância com as demandas das pessoas idosas, trabalhando na perspectiva de viabilizar os direitos do idoso nos diferentes espaços da sociedade civil.

O PICG também conta com uma equipe multidisciplinar, interinstitucional e intergeracional, que enriquece o projeto, uma vez que possibilita o envolvimento de diferentes áreas como: Serviço Social, Enfermagem, Psicologia, Sociologia, entre outras.

Nesse espaço, a atuação do Serviço Social tem um papel fundamental: reconhecer o processo de envelhecimento como uma questão social, e, a partir desse reconhecimento, propiciar aos idosos espaços de discussão, análise e reflexão sobre as suas demandas; além disso, a atuação do serviço social contribui para a mudança da representação social do idoso tanto no meio acadêmico como na sociedade, oportunizando as relações entre diferentes gerações e o seu desenvolvimento pessoal e social.

\section{RESULTADOS E ANÁLISE}

O contato permanente com as idosas durante a realização do estágio junto ao NETI, bem como a realização das entrevistas na modalidade "trajetórias de vida", permitiu estabelecer uma análise dos temas propostos: envelhecimento e empoderamento, com o objetivo de contribuir para a desmistificação do estereótipo criado pela sociedade em torno da velhice ou da pessoa idosa como incapaz. Os depoimentos a seguir demonstram que as idosas integrantes do PICG conquistaram autonomia, autoestima e sentem-se valorizadas e mais capazes para intervir junto a seus pares, graças à participação nos cursos oferecidos pelo NETI.

O NETI como um espaço de acolhida e valorização das idosas - "[...] a minha entrada no NETI mudou tudo na minha vida, através do NETI eu cresci [...]” (Antonieta $\left.{ }^{8}, 2012\right)$ )"

Com o envelhecimento e a viuvez, muitas idosas sentem necessidade de socialização, de sair em busca de novas amizades e de melhor qualidade de vida, no intuito de fugir da solidão e de evitar doenças de fundo emocional, como depressão, entre outras. Espaços como centros de convivências e projetos oferecidos pelas Universidades para a Terceira Idade são procurados por essas mulheres, pois passam a se sentir valorizadas e incluídas na sociedade, como pode-se constatar nas falas das entrevistadas que passaram a se inserir no PICG/NETI.

[...] uma amiga disse: eu estou fazendo um curso tão bom no NETI, é muito bom porque você vai se preparar para a velhice. E eu fui conhecer o NETI. Meu Deus, como aprendi no NETI, passei a gostar da minha pessoa, porque eu sempre só olhava para os outros, mas aí eu aprendi a gostar de mim, aprendi a olhar para mim, aprendi a entender a velhice, a me preocupar com a minha velhice, que é o mais importante [...] (CHIQUINHA, 2012)

O NETI foi uma história muito interessante, porque a minha mãe estava no hospital [...] e eu ficava no hospital com ela [...] e eu fui consultar um dermatologista [...]. Ele conversou bastante comigo, perguntou o que eu fazia, eu disse que era dona de casa e cuidava da minha mãe doente. Aí ele perguntou: e o seu lazer? Eu disse: estou aposentada e eu não tenho lazer. Aí ele disse: a senhora precisa ter um lazer, uma ocupação [...], a senhora tem que fazer coisas diferentes. Aí no mesmo dia, a assistente social providenciou a minha entrada no NETI [...] (CORA, 2012)

Nas falas das entrevistadas, a entrada no NETI seguiu o mesmo itinerário, ou seja, antes do NETI, elas eram donas de casa, aposentadas ou cuidadoras, como no caso de Cora. Na citação de Chiquinha, fica

$8 \quad$ Foram atribuídos nomes de mulheres famosas que se destacaram na história do Brasil e de Santa Catarina para cada idosa entrevistada, resguardando assim suas identidades. 
evidente a melhora da autoestima, quando diz que "aprendeu a gostar de si". Todas, de alguma forma, foram em busca de uma socialização, de um passatempo, de um lazer e, acima de tudo, de conhecimento, através da inserção em grupos, como confirma Antonieta:

Depois que eu cheguei no NETI, nunca mais saí. O NETI mudou muita coisa na nossa vida, quando nós chegamos no NETI, a gente conheceu várias pessoas e mudou a nossa maneira de ver a vida, de como envelhecer bem. E isso o NETI ensinou, que a gente tem uma capacidade incrível, é só a gente querer, de memória, de socialização, e, por isso, o NETI é completo (ANTONIETA, 2012).

Nas falas das entrevistadas, constata-se um valor grande para a socialização, enquanto recuperação do valor social e do bem-estar social, conforme depoimento de Antonieta. A participação nos grupos e no caso, no NETI, contribuiu para as entrevistadas gerarem novas redes de amizade, inserirem-se em espaços de socialização, refletirem sobre sua autonomia perante a sociedade e a família e contribuírem para uma nova visão sobre o processo de envelhecimento. De acordo com Debert (1994), "[...] a velhice é um momento em que a mulher liberada de todos os papéis sociais próprios das fases anteriores da vida pode enfim se dedicar a realização de sua pessoa" (DEBERT, 1994, p. 4).

\section{A concepção de envelhecimento e a discriminação dos idosos pela sociedade - "dizem que todos são iguais perante a lei" (Anita, 2012)}

Constata-se, por parte de algumas entrevistadas, a dificuldade de encarar a velhice, e, por esse motivo, atribuem muita importância ao envolvimento delas umas com as outras, especialmente no período após a aposentadoria, e no dito "ninho vazio". Ocorre uma busca do aprender a envelhecer, como vê-se a seguir: "E aí uns meses depois veio minha aposentadoria. E aí eu fiquei com a síndrome do ninho vazio, que muitas pessoas falam, os filhos casados, a mãe morreu e agora passei a morar sozinha [...]" (ANITA, 2012), "A velhice é um monstro, é uma coisa! A gente só depende dos outros, senti dor no braço, dor na perna [...], por isso a gente tem que se preparar, tem que vir para o NETI [...], e foi o que eu fiz" (CHIQUINHA, 2012), "Hoje eu me sinto uma pessoa valorizadíssima, por tudo que eu faço, pelo ser que eu sou, pelo respeito das pessoas [...]" (CORA, 2012).

$\mathrm{Na}$ fala de Cora, pode-se perceber sua satisfação em se sentir valorizada pelo fato de levar os conhecimentos apreendidos através do PICG/NETI, para pessoas humildes que tinham pouca ou nenhuma escolaridade, nos municípios onde o projeto PICG era solicitado.

Antonieta relata suas experiências vivenciadas no PICG, ressaltando que o repasse de informações e conhecimentos aprendidos ao longo de seus estudos no NETI não era somente para os idosos; que o seu trabalho também se estendeu para as crianças em escolas e grupos de mães, nos locais onde o projeto era solicitado, conforme depoimento:

Eu me inscrevi para o PICG em 2005 e em 2006 comecei a participar de vários intercâmbios: estive no Sul do estado em Praia Grande [...] no segundo dia eu falei sobre saúde de modo geral, [...] no terceiro dia fomos numa escola visitar crianças [...] falei com eles sobre o respeito ao idoso [...] e depois as crianças começaram falar que também tinham vovó, que estas contavam histórias para eles [...] depois eu falei que as pessoas também envelhecem, que o corpo modifica, mas o sentimento permanece o mesmo [...] (ANTONIETA, 2012).

Para as entrevistadas, a visão do envelhecimento está relacionada à liberdade de chegar à terceira idade, a de continuar ativa e participante, sentindo-se úteis no seu grupo e no caso acima citado, nos grupos visitados, como também o de não "dever nada para ninguém".

"Eu faço o que quero, como o que eu quero, não tem ninguém para dizer não faz isso, eu tenho meu dinheiro, não dependo de ninguém, eu tenho uma vida legal, não posso reclamar [...]" (CHIQUINHA, 2012).

Então chegar nessa idade é uma experiência de vida porque agora eu faço muita coisa que não fazia quando era jovem: ir ao shopping, no cinema, fazer algum tipo de compra que eu não fazia antes, eu era muito restrita, hoje não, eu tenho cara de pau para fazer muitas coisas [...] (TARSILA, 2012).

A volta aos estudos também proporcionou às entrevistadas uma nova visão sobre o envelhecimento, principalmente no que diz respeito ao reconhecimento de seus direitos e deveres, proporcionados pelas 
políticas para as pessoas idosas, como a Política Nacional do Idoso, de 1994, e o Estatuto do Idoso, de 2003. Constataram que podem reivindicar o que lhe é de direito e perceber as conquistas e falhas dessas leis, conforme relata Anita:

A carta dos direitos humanos diz que todos são iguais perante a lei, porque tem que ter um estatuto do idoso? Se eu precisar requerer um dinheiro atrasado, que o governo me deve, tenho que entrar com advogado e só eu recebo, o outro não recebe, então essa jurisdição brasileira dificulta, a Constituição Federal diz que eu sou igual, porque meus direitos são diferentes dos jovens? (ANITA, 2012).

No depoimento de Anita, constata-se uma crítica em relação às políticas que são criadas ou às leis que já existem e não são colocadas em prática, ou seja, já existem leis que asseguram os direitos de igualdade dos seres humanos, um exemplo é a Carta dos Direitos Humanos, que, em seu art. 10: “Todos os seres humanos nascem livres e iguais em dignidade e em direitos" ${ }^{~}$. Nesse sentido, Anita reforça a dificuldade que existe no nosso país de levar a sério a legislação, ou seja, na maioria dos casos, as leis estão muito bonitas no papel, mas, quando é para colocar em prática, a realidade é outra.

As falas a seguir ressaltam a dificuldade na efetivação de políticas públicas para idosos, bem como o preconceito e a discriminação sofrida pelos idosos em uma sociedade que sobressai a falta de respeito dos jovens para os velhos:

Em relação à valorização do idoso, acho que ainda temos que fazer muita coisa [...] tem que mudar essas políticas públicas que falam tanto de inclusão do idoso, apesar de que eles já estão incluídos no senado, na câmara, mas quem está no poder não se acha idoso, não olha para os outros idosos que estão aqui embaixo, mas nós temos que fazer alguma coisa, até a participação ativa nas entidades, nas lutas, participar para ter melhor condição de vida, e fazer valer nossos direitos [...] (ANTONIETA, 2012).

Eu queria que mudasse o respeito na nossa sociedade em relação ao velho. Se tem respeito, tem tudo! $\mathrm{Na}$ sociedade poucos respeitam os idosos. Ontem eu saí do NETI, comprei umas coisinhas e peguei um ônibus. Uma jovem perguntou: 'você quer que eu ajude a pegar essas sacolas?'. E na hora de saltar, ela me ajudou a levar as sacolas [...]. Mas isso é difícil, ver um jovem ter respeito com a pessoa idosa, isso porque ela deve ter na família alguém que ela ama, que é idosa [...] (CORA, 2012).

A gente ainda está um pouco em segundo plano, tem muito preconceito ainda sobre a velhice. Eu não, graças a Deus, eu me sinto bem com a idade que eu tenho, mas eu vejo preconceito por certo tipo de pessoas mais novas, vejo isso no supermercado, no ônibus, às vezes até em banco [...] eu sou assim, se eu estou numa fila de banco, eu não ligo se tem um jovem na minha frente, claro, se a fila é nossa, tem que ser respeitada [...] (TARSILA, 2012).

Antonieta faz uma crítica em ralação a um grande número de políticos que são idosos, mas que têm dificuldade em se perceber como idosos. Tarsila reforça a importância da participação dos idosos em diferentes esferas da sociedade civil, já que é uma forma de assegurarem seus direitos. Por sua vez, Cora e Tarsila se referem à falta de respeito dos jovens em relação ao idosos. O Estatuto do Idoso, em seu capítulo II, art. 10, enfatiza o respeito da pessoa idosa, bem como a dignidade e a liberdade: é obrigação do estado e da sociedade assegurar à pessoa idosa a liberdade, o respeito e a dignidade, como pessoa humana e sujeito de direitos civis, políticos, individuais e sociais, garantidos na Constituição e na Lei (CF, 1988).

O reconhecimento das capacidades gera autoconfiança e alavanca o empoderamento “participando do projeto, ajudei as pessoas sair da situação que estavam” (Cora, 2012)

A inserção das idosas no PICG e a sua atuação como monitoras nas ações desenvolvidas junto a grupos em diversos municípios do Estado de Santa Catarina contribuiu para serem reconhecidas e iniciarem um processo de empoderamento, como pode-se constatar no depoimento a seguir:

A lição de vida que ficou para mim com a participação no PICG/NETI é que ajudei as pessoas a saírem

9 Disponível em: <http://portal.mj.gov.br/sedh/ct/legis intern/ddh bib inter universal.htm $>$. Acesso em: $3 \mathrm{dez}$. 2012. 
da situação que estavam, até hoje eu ajudo. Uma vez, eu estava em um lugar e tinha uma mulher muito rica, esposa de um construtor da cidade, e ela disse: eu sou mais jovem que a senhora e a senhora me deu uma lição de vida que eu jamais vou esquecer e [...] eu vou lhe imitar [...] esses dias encontrei ela numa academia de letras em São Paulo [...] e ela veio me abraçar e dizendo: você já viu meu livro? Então, através do meu exemplo, ela saiu daquela situação [...] (ANITA, 2012).

No relato de Anita, pode-se constatar que o seu processo de empoderamento perpassou a autoconfiança que lhe foi transmitida pela "mulher muito rica", que se inspirou em seus dons, no caso escrever poesias, que a exemplo de Anita, também publicou um livro. Nesse caso, ocorreu um processo de empoderamento em ambas, na mulher que inspirou-se na força e na coragem de Anita; e em Anita, que fortaleceu o empoderamento psicológico à medida que foi reconhecida e valorizada como palestrante, idosa detentora de conhecimentos e escritora de livros. Aqui fica explícito o apoio recebido por Anita pelas integrantes do NETI através do PICG, que, ao repassar seus conhecimentos em determinado local, superou as expectativas, conforme Lisboa:

A superação dessa situação exige, em primeiro lugar, a tomada de consciência por parte dessas mulheres, de seu poder social, político e psicológico; em segundo lugar, que sejam capacitadas para atuar com responsabilidade no espaço público na defesa de seus direitos (LISBOA 2007).

A experiência de atuarem como monitoras, através do PICG, foi muito significativa para a maioria das idosas, como se pode constatar nos depoimentos:

A lição de vida que levo do PICG, dos lugares que conheci, de que as pessoas são diferentes, os lugares que vivem, como é diferente uma pessoa do sitio, que não tem nossa informação. Aqui na sociedade, tudo é mais dinâmico, lá fora os idosos ainda estão lavando, passando, estão ainda dando o dinheiro para a família. Os idosos não estão tendo uma vida de idoso [...] (CORA, 2012).

A lição de vida que deixo sobre o PICG, que as pessoas devem curtir política, eu falo da política para meus filhos, tento desmistificar, mostrar que a política é bonita, que a gente pode trabalhar o lado bonito da política, então saber escolher, saber votar e escolher os governantes [...] (ANTONIETA, 2012).

Dessa forma, o PICG/NETI serviu como uma alavanca e estímulo para que essas mulheres pudessem se sentir valorizadas, afirmando sua autoestima e sentindo-se capazes para realizar atividades que antes não eram capazes de fazer. Atualmente, Anita faz parte de várias academias de letras, fato esse que relata com muito orgulho:

[...] e resolvemos fundar a Associação dos Poetas Catarinenses, eu e a Maria Rita somos as fundadoras, ela hoje é a personalidade Jurídica [...] e aí essa associação resolveu fundar a Academia de Letras de São Jose, lá na academia eu sou fundadora também, eu ocupo a cadeira 24 [...] e aí resolvemos fundar a Academia de Letras em Biguaçu, lá eu ocupo a cadeira número 20. Mais recentemente fundamos a Academia de Letras de São Pedro Alcântara, lá eu não quis uma cadeira porque é muito longe e eu já tenho tantas outras, lá sou acadêmica honorária, aí fundamos a Academia de Letras de Governador Celso Ramos, lá eu também só sou acadêmica correspondente, não tenho cadeira, porque não tenho mais espaço de trabalhar nessa idade que estou, mas tudo isso é gratificante [...] (ANITA, 2010).

Anita também é autora de livros e poemas, alguns editados pelo NETI. Chiquinha, além de permanecer voluntária do NETI há 18 anos, também faz parte do Grupo de Seresta e Grupo de Canto Vozes da Ilha do NETI, motivo de muito orgunho para a entrevistada:

E o Projeto Seresta sempre é convidado a participar em algum lugar, eles que convidam a gente, alguém vê e entra em contato, ontem mesmo entraram em contato comigo para cantar na Academia de Letras em São José, já cantamos uma vez e convidaram para cantar de novo (CHIQUINHA 2010).

Cora permanece voluntária do NETI, da Associação do Hospital Universitário e participante do grupo de canto do NETI. Tarsila também é voluntária do NETI, dá aula de artesanato para as idosas na Escola da Marinha:

"Na Marinha eu comecei a fazer esse trabalho, e eles começaram a me pagar, lá eu ensino para oito alunas, e nós temos uma sala especial para isso, lá tem yoga, cromoterapia. E esses trabalhos manuais, a 
Marinha dá todo material, e a gente que faz (TARSILA, 2012).

Antonieta participa de diversos cursos do NETI, bem como da Pastoral da Pessoa Idosa: "E hoje eu faço os cursos no NETI, de Italiano e a Oficina de Política que faz parte da Capacitação do PICG”.

Essas idosas demonstram que a experiência de chegar na terceira idade não significa o fim do ciclo de suas vidas, mas o início de novos projetos e realizações de muitos de seus sonhos, o que comprova que o ser humano pode aprender e evoluir em todas as fases de sua vida.

\section{Considerações finais}

O processo de empoderamento dessas idosas pode ser constatado através de seus relatos durante as entrevistas, mas sobretudo através da observação participante no estágio no PICG, pois a maioria delas é acompanhada tanto nas visitas aos municípios, representando o projeto, como em vários outros espaços em que elas se fizerem presentes exercendo algo pelo NETI. Tem-se especial orgulho em compartilhar "a ocupação de cadeiras" nas diferentes academiais de letras citadas por Anita e o trabalho valorizado que Tarsila exerce junto à Marinha em Florianópolis/SC.

Acompanhando os relatos sobre o trabalho das idosas junto aos grupos de convivência nos municípios, constatou-se que as integrantes do NETI serviram de exemplo para que outras pessoas idosas também pudessem iniciar seu processo de emponderamento. Constatou-se, através das trajetórias de vida, que as mulheres entrevistadas que participaram das atividades oferecidas pelo PICG/NETI encontram-se inseridas em inúmeras outras atividades, espaços de socialização, como a Academia de Letras da Grande Florianópolis, são escritoras, professoras de bordado, voluntárias em outras instituições, entre outras. A passagem pelo NETI propiciou autoestima e autoconfiança para se sentirem capazes de ocupar outros espaços além da esfera familiar, levando seu exemplo para outras idosas.

\section{REFERÊNCIAS}

DEBERT, Guita. Gênero e Envelhecimento. Os Programas para a Terceira Idade e o Movimento dos Aposentados. Revista Estudos Feministas, v. 2, 1994, p. 35-51.

FREITAS, Rosana de Carvalho Martinelli; LISBOA, Teresa Kleba. Serviço Social em Revista. Publicação Comemorativa aos 50 anos do curso de Serviço Social da UFSC, Nova Letra Gráfica e Editora, 2009.

GRUNEWALD, Virgínia. (Org.) NETI: a construção de um caminho na gerontologia. Florianópolis: Copyflo, 1997.

Jornal Vida e Cidadania. Disponível em: <弚nalvidaecidadania@hotmail.com>. Acesso em: 15 abril 2009.

MADUREIRA, M. C. S.; MOREIRA, D. R et all. Intercambio Comunitário em Gerontologia. In: EXTENSIO - Revista Eletrônica de Extensão no 3, ano 2005.

NETI. História do núcleo de estudos da terceira idade. Disponível em: <http://www.neti.ufsc.br> Acesso em $0 / 09 / 2012$.

LISBOA, T.; GONÇALVES, C. Rita. Sobre o método da história oral em sua modalidade trajetórias de vida. 
Revista Katálysis. Florianópolis v. 10 n. esp. p. 83-92, 2007.

LISBOA, T. K. Empoderamento de mulheres e participação na gestão de políticas públicas. Anais II Seminário Nacional: Movimentos Sociais, Participação e Democracia. Universidade Federal de Santa Catarina. Florianópolis, 2007.

LISBOA, T. K. Empoderamento. Palestra proferida no Encontro comemorativo 30 anos do Núcleo de Estudos da Terceira Idade, 2012.

PASCHOAL, P. M. Sérgio. Envelhecimento na perspectiva de gênero. São Paulo, Vetor, 2006. 